\title{
Using Balance Score Card to Evaluate Performance of High-Tech Companies
}

\author{
Lu Kebin $^{1}$, Wang qiang ${ }^{2}$ and Zhu Benxiao ${ }^{3}$ \\ ${ }^{1}$ Anhui Xinhua University, Commercial College, Hefei, 230088, China \\ ${ }^{2}$ Military General Logistics Department, East China military material purchasing \\ Bureau, Shanghai 200437, China \\ ${ }^{3}$ Anhui Xinhua education group company, Hefei, 230088, China \\ Wgq101yq@163.com
}

\begin{abstract}
This paper analyzes the characteristics of High-tech Enterprise performance evaluation and gives design principles of its risk investment performance evaluation, and makes an empirical study about five auto companies on the performance evaluation of risk investment based on the BSC, to make up for the drawback of traditional performance appraisal which pays too much attention to the financial indicators, to provide a useful exploration for the comprehensive evaluation of risk investment performance of High-tech Enterprise.
\end{abstract}

Keywords: High-tech Enterprises, Risk Investmen, BSC, Empirical Research

\section{Introduction}

At the beginning of the 1900s, domestic and foreign scholars have embarked on the study of the system of performance evaluation in enterprises. James C. Hayton[1] (2005) has made a study on the performance of high-tech enterprises, exploring the relationship between organizational reputation and human resource capital, revealing a strong positive correlation between the two factors. Li Jianli(2006)[2] bring forth the existence of cost on the use of capital for decision-makers by calculating the cost of capital of investment in projects, using the theory and methodology of Eonomce Value Added (EVA). Fan Hong, Wang Min and Pan Yueqi (2010)[3] points out the importance of capital in guaranteeing the existence and continued development of enterprises, emphasizing the need of large amount of capital to support $R \& D$, production and sales of high-tech companies. The capital made available by risk investment can ease the lack of capital and greatly advances the innovation of high-tech industries, which leads to their growth. Drawing on the Grey System Theory Zhou Xiaozhi (2013)[4] constructed an evaluation model system including financial and non-financial factors as indicators to evaluate the risk investment in innovation-driven high-tech SMEs. Lu Kebin, Wang Qiang and Zhou Hui (2013)[5] studies the means of the entrance of capital to innovation and its influence on the innovation performance of high-tech SMEs. Quan Rong (2014)[6] constructs a model which reveals the impacts of risk investment on the performance of enterprises using multi-regression analysis with the software STATA.

The Balanced Score Card, BSC, is a new system of performance management in the four perspectives of finance, customers, internal operation, learning and growth to turn the organization strategies to operable and measurable indicators and objectives. It was developed by Robert S. Kaplan and David P. Norton in 1992 in their first thesis on BSC---The Balanced Score Card Measures that Drive Performance in Harvard Business Review. Afterwards, BSC began to receive more 
attention from industries and was gradually applied to the practice of performance evaluation of enterprises [7]. Zhang Daohai [8] and Zhang Tongjian identifies the natural fitting between BSC and the performance evaluation of high-tech SMEs, thus providing an effective strategy for evaluating the performance of high-tech SMEs. Tao Qing [9] draws on the method of BSC in performance evaluation and introduces some non-financial indicators in the predication of financial crisis and management. Because of the Comprehensiveness, faithfulness and accuracy of BSC in analyzing financial crisis in enterprises, it is easier to be widely used by enterprises.

The objectives of performance evaluation of high-tech enterprises will provide basis for their strategic long term development. Enterprises are in demand of guidance of theories which has practical values. At the same time, due to the shifting dynamics of internal and external environment in which enterprises face, the evaluation of performances of risk investment should not only take into account financial factors but also customers, internal and external factors to gain a comprehensive outlook on the value and development status of enterprises. The thesis uses BSC to evaluate the performance of enterprises instead of single financial indicators such as DuPont Analysis System, EVA and trend analysis approach which lacks comprehensiveness in evaluating performance and analyzing operational problems systematically, leading to the failure to integrate strategic goals of enterprises with strategic management tools. The originality of the research of this thesis lies in helping administrators in discovering problems in operation in a timely manner, constructing design principles of evaluation of risk investment performance of high-tech enterprises, combining quantitative and qualitative methods, and analyzing problems through empirical data, and providing evidences to evaluation of performance of the automobile industry. It not only explores the highlights of achieving strategic objectives and revenue and net profit, but also focuses on the customer loyalty as well as $\mathrm{R} \& \mathrm{D}$, thus providing valuable references for enterprises.

\section{Risk Investment and Performance Evaluation in High-tech Enterprise}

High-tech enterprises performance evaluation is using scientific, rigorous evaluation methods and based on pre-determined business targets, to analyze the high-tech enterprise's operating results within a certain period, which including financial benefits, anti-risk capability, development capacity indicators etc. There are significant differences in the performance evaluation of high-tech enterprises and traditional enterprises.

First, the evaluation focused on intellectual capital and intellectual capital, which are corporate intangible assets. Compared to traditional enterprises, high-tech enterprises' competitiveness depends on intangible capital instead of tangible capital, especially intellectual capital [10].

Second, the different development period that the high-tech enterprise in will result in different evaluation criteria. The life cycle of the high-tech industry in general will go through the stage of seed, establishment, growth, maturity and decline. In different life cycles, enterprises are facing different internal and external environment, which determines that the performance evaluation criteria and evaluation methods for each life cycle of high-tech enterprises may not be the same.

Finally, we evaluate the enterprise's condition based on the strategic point of view. Performance evaluation can transfer the enterprise's strategic objectives into concrete, actionable targets that most people agreed with, which will contribute to the specific implementation of strategic objectives of high-tech enterprises, making the performance evaluation system resolve into the whole strategic management 
process, and revealing the role that the performance evaluation plays in the high-tech enterprise strategy management.

Since the third technological revolution, the high-tech industry, an important pillar of modern industry, has become an important indicator to measure a country's comprehensive national strength. However, the development of modern high-tech industries often hinges on capital, talent, technology and other factors, so that the risk investment came into being under such circumstance. Since the first introduction in the United States, the risk investment has been known as "the embedded diamond in the US economy" for its contributions in promoting high-tech industries in the United States. The development of risk investment and high-tech industries complement each other, as high-tech enterprises develop and expand with the support of risk investment, while the venture capital also achieve a tremendous capital appreciation in the same process. The risk investment, as an emerging investment and financing method, has gained a huge amount of invest return but also facing huge risk. American scholar Amrer believes that for the capital owner, the risk investment is to bet on a high-risk business, as the investment may never return, or it may be returned as hundreds times of earning. The investment is long-term, and by the means of equity participation. In addition to higher risk, the investment objects are often those new businesses with rapid growth, so that the risk investment is expected to get huge profits. The American economist Douglas Greenwood opined that "venture capital is ready to take risks, it is prepared for a rapid development of promising new companies or new product development funding initially subjected to risk, rather than for the purchase of capital and the company or product related to the various assets. "Since risk investment was brought in to our country, it is valued by many people. However, the successful risk investment accounts for only a small part, the main reason is the lack of effective risk management and performance evaluation of investment projects and venture capital companies before and after the investment, which requires companies or risk investment companies to establish a scientific and reasonable performance evaluation system to achieve this goal.

Based on the performance evaluation of high-tech enterprises and the characteristics of risk investment, this paper argues that the design of high-tech enterprise risk investment performance evaluation should follow the following principles:

(1) The principle of purpose. The so-called performance evaluation is using evaluation methods to assess the enterprise's operating results during a certain period. It has a sense of purpose, namely to evaluate what, and how to evaluate.

(2) The principle of adaptability. Due to the unique nature of risk investment firms (high-tech, high-risk, high investment, high return), the performance evaluation system should also adapt to the nature of the business, that is to say the performance evaluation system should fully reflect all aspects of the enterprise, not only limit to evaluate corporate financial indicators, but also should taking into account other indicators as well.

(3) The principle of binding qualitative and quantitative aspects. Risk investment firms are different from traditional enterprises, which requires the evaluation system should not only evaluate corporate short-term profitability and other short-term indicators, but should also ensure the long-term indicators such as the corporate's safety and growth etc. To design the performance evaluation indicators, we should consider the balance between financial and non-financial indicators, thus to evaluate these indicators from both qualitative and quantitative aspects. 


\section{The Statistical Study of Risk Investment Performance Evaluation in Automobile Company}

Automobile companies in China have great development in recent years, but as the outbreak of global financial crisis, the virtual economy crisis spread to the real economy, which led China's automobile industry, especially those high energy-consuming automobile companies to a cold winter. JAC automobile company, which experiencing a strategic transformation, was also suffered from this far-reaching crisis. At the same time, because of the prices of raw material and oil keep rising, the RMB yuan appreciating, the launch of the energy conservation policy, as well as the company's expansion in both domestic and overseas market, all these reasons drove the marketing expenses for the new products increase to some degree.

The Balanced Score Card (BSC)includes four sub-objectives which are not isolated with each other, but linked by causal relationship in a layer structure (Figure 1). The sub-objective in the learning and growth level has been achieved, which further promote the improvement of the customer and market level, and ultimately achieve the objective of the financial level and company's mission and vision [11].

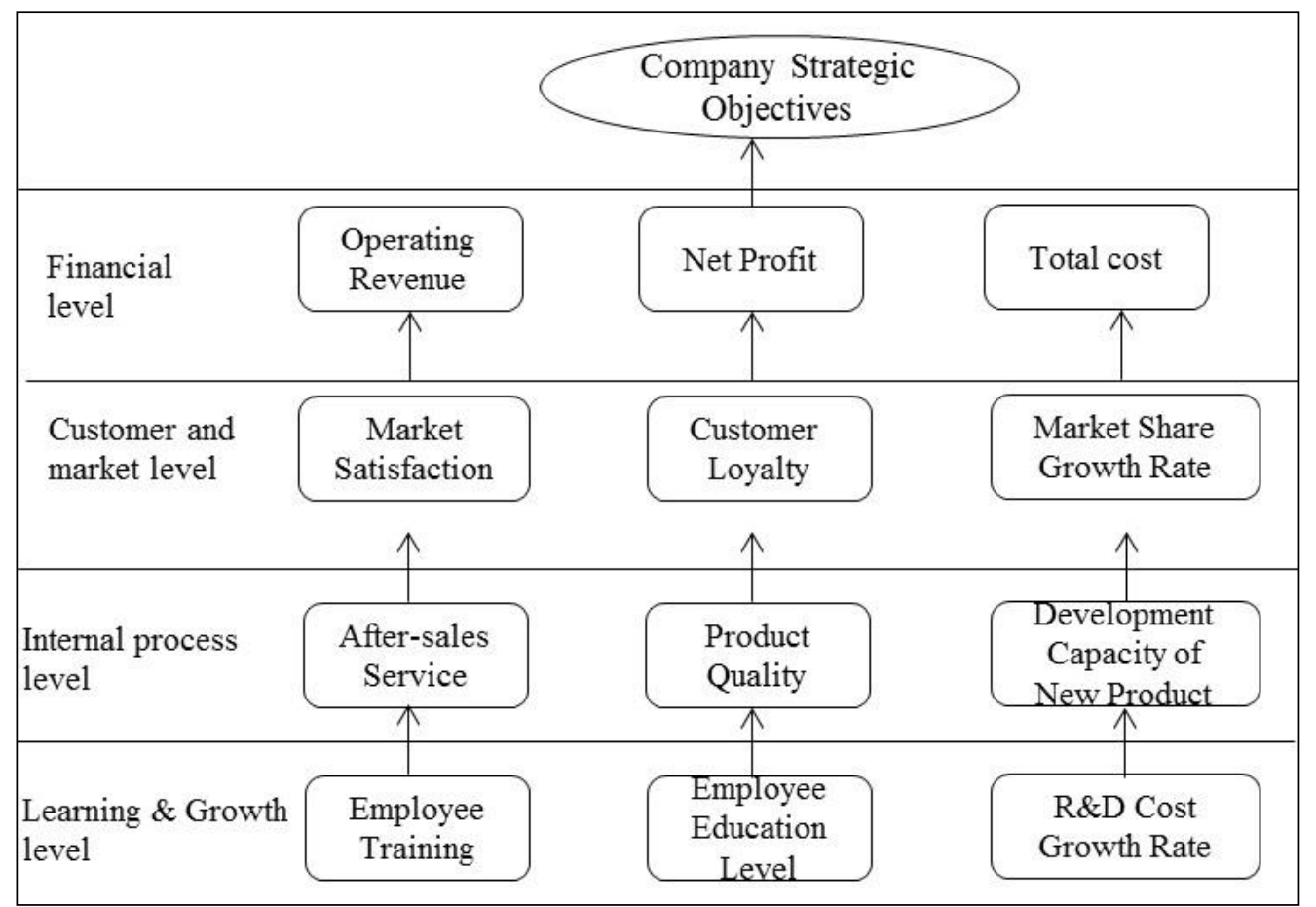

Figure 1. The Strategy Map of the Automobile Company

(A) Performance Evaluation Model and Judgment Matrix

We firstly conduct interviews and surveys with senior executives from relevant departments in five automobile companies, and apply the Delphi method to extract 13 sub-objectives as evaluation indicators, therefore we construct the performance evaluation model as follows: 


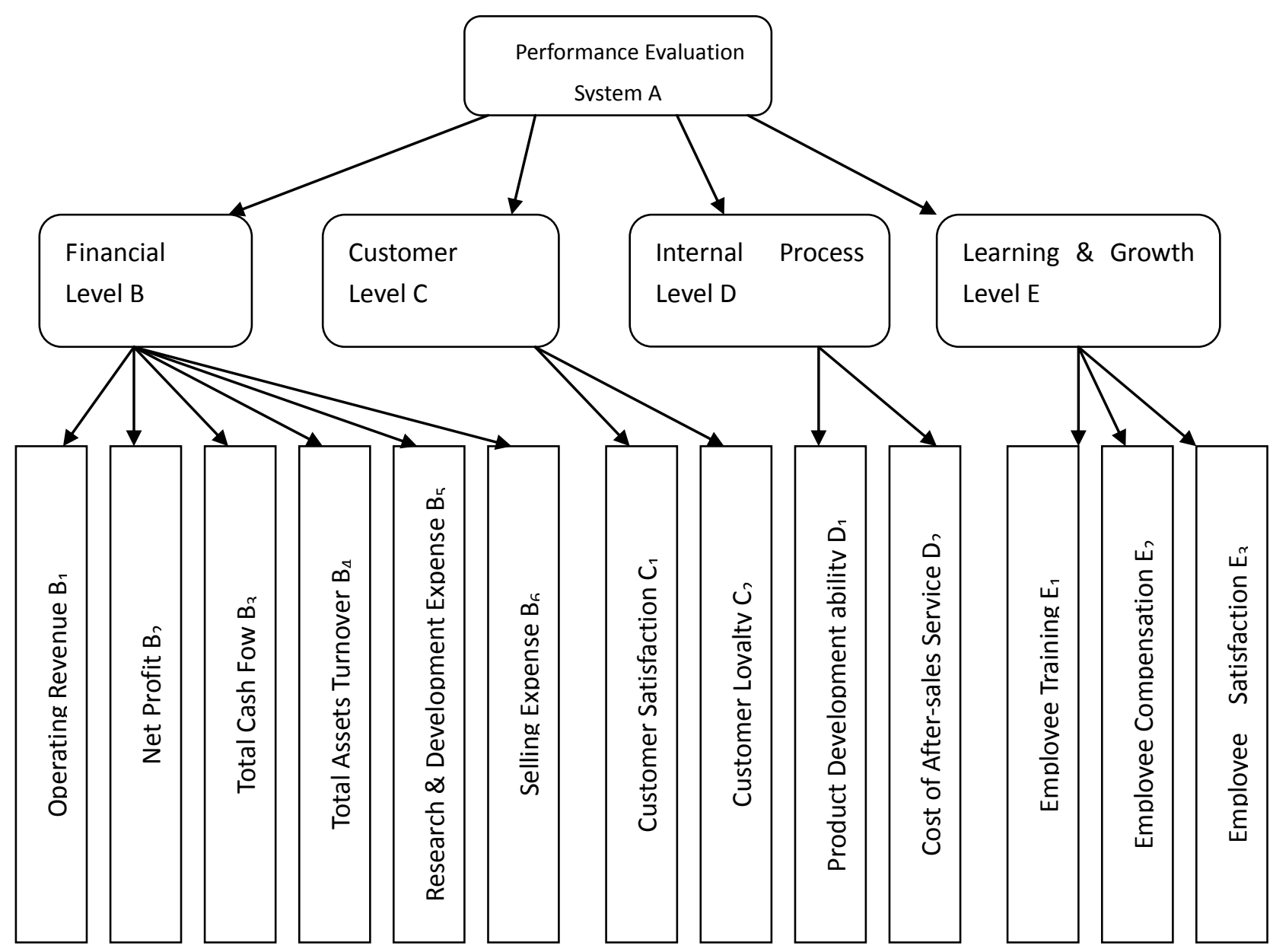

Figure 2. Enterprise Performance Evaluation Model

In the actual research, by using the expert opinions method, we conduct research on the executives from different departments of the company and teach each one of them about the BSC indicators system as well as how to compare the indicators and how to use scale to judge. Through multiple anonymous surveys, we finally obtain the important data for each BSC indicator:

Table 1. Judgment Matrix A of Relative Important Degree for BSC Levels

\begin{tabular}{ccccc}
\hline A & B & C & D & E \\
\hline B & 1.00 & 3.00 & 3.20 & 2.00 \\
C & 0.33 & 1.00 & 2.25 & 1.50 \\
D & 0.31 & 0.44 & 1.00 & 0.75 \\
E & 0.50 & 0.67 & 1.33 & 1.00 \\
\hline
\end{tabular}

Get The BSC index of target layer elements of judgement matrix: 


$$
A=\left[\begin{array}{cccc}
1 & 3 & 3.2 & 2 \\
0.33 & 1 & 2.25 & 1.5 \\
0.31 & 0.44 & 1 & .075 \\
0.50 & 0.67 & 1.33 & 1
\end{array}\right]
$$

Table 2. Judgment Matrix B of Relative Important Degree for Indicators in Financial Level

\begin{tabular}{|c|c|c|c|c|c|c|c|c|}
\hline B & $\mathrm{B}_{1}$ & & $\mathrm{~B}_{2}$ & & $\mathrm{~B}_{3}$ & $\mathrm{~B}_{4}$ & $\mathrm{~B}_{5}$ & $\mathrm{~B}_{6}$ \\
\hline $\mathrm{B}_{1}$ & 1.00 & & 0.45 & & 1.45 & 1.75 & 2.00 & 3.75 \\
\hline $\mathrm{B}_{2}$ & 2.22 & & 1.00 & & 2.65 & 3.75 & 4.75 & 3.00 \\
\hline $\mathrm{B}_{3}$ & 0.68 & & 0.38 & & 1.00 & 1.35 & 2.28 & 1.75 \\
\hline $\mathrm{B}_{4}$ & 0.57 & & 0.27 & & 0.74 & 1.00 & 1.58 & 2.25 \\
\hline $\mathrm{B}_{5}$ & 0.50 & & 0.21 & & 0.44 & 0.63 & 1.00 & 1.10 \\
\hline $\mathrm{B}_{6}$ & 0.27 & & 0.33 & \multirow{2}{*}{\multicolumn{3}{|c|}{3.757}} & 0.91 & 1.00 \\
\hline \multirow{6}{*}{ The } & 1 & 0.45 & 1.45 & & & & & \\
\hline & 2.22 & 1 & 2.65 & 3.75 & 4.75 & 3 & & \\
\hline & 0.68 & 0.38 & 1 & 1.35 & 2.28 & 1.75 & & \\
\hline & 0.57 & 0.27 & 0.74 & 1 & 1.58 & 2.25 & & \\
\hline & 0.50 & 0.21 & 0.44 & 0.63 & 1 & 1.1 & & \\
\hline & 0.27 & 0.33 & 0.57 & 0.44 & 0.91 & 1 & & \\
\hline
\end{tabular}

Table 3. Judgment Matrix $\mathbf{C}$ of Relative Important Degree for Indicators in Customer Level

\begin{tabular}{ccc}
\hline $\mathrm{C}$ & $\mathrm{C}_{1}$ & $\mathrm{C}_{2}$ \\
\hline $\mathrm{C}_{1}$ & 1.00 & 0.58 \\
$\mathrm{C}_{2}$ & 1.72 & 1.00 \\
\hline
\end{tabular}

The $C=\left[\begin{array}{cc}1 & 0.58 \\ 1.72 & 1\end{array}\right]$ 
Table 4. Judgment Matrix D of Relative Important Degree for Indicators in Internal Process Level

\begin{tabular}{ccc}
\hline $\mathrm{D}$ & $\mathrm{D}_{1}$ & $\mathrm{D}_{2}$ \\
\hline $\mathrm{D}_{1}$ & 1.00 & 0.50 \\
$\mathrm{D}_{2}$ & 2.00 & 1.00 \\
\hline
\end{tabular}

The $D=\left[\begin{array}{cc}1 & 0.5 \\ 2 & 1\end{array}\right]$

Table 5. Judgment Matrix E of Relative Important Degree for Indicators in Learning and Growth Level

\begin{tabular}{cccc}
\hline $\mathrm{E}$ & $\mathrm{E}_{1}$ & $\mathrm{E}_{2}$ & $\mathrm{E}_{3}$ \\
\hline $\mathrm{E}_{1}$ & 1.00 & 0.80 & 1.50 \\
$\mathrm{E}_{2}$ & 1.25 & 1.00 & 2.25 \\
$\mathrm{E}_{3}$ & 0.80 & 0.44 & 1.00 \\
\hline
\end{tabular}

The $E=\left[\begin{array}{ccc}1 & 0.8 & 1.5 \\ 1.25 & 1 & 2.25 \\ 0.8 & 0.44 & 1\end{array}\right]$

(B) Calculating weight

Mainly USES the mathematical methods of "root" the Lord of the matrix eigenvector, is made up of index weight at the same level of weight vector. Calculation steps are as follows.

The first step is to calculate the judgement matrix of each line product, calculating formula for:

$M_{i}=\prod_{j=1}^{n} b_{i j}(i=1,2,3,4)$

Get the product of the vector M:

The $M=\left(M_{1}, M_{2}, M_{3}, M_{4}\right)^{T}$

The second step, calculate the NTH root of the $M_{i}$, Calculating formula for:

$W_{i}=\sqrt[n]{M_{i}}$

When the square root of the fourth power(n=4), can get the root vector for the 
$\operatorname{vector}_{W_{i}}^{-}$.

The third step, the vector orthogonalization can get the weight vector, calculating formula for:

$$
W_{\mathrm{i}}=\frac{w_{i}}{\sum_{i=1}^{n} w_{i}}
$$

Wants weight vector is obtained:

$W=\left(\begin{array}{llll}W_{1}, & W_{2}, W_{3}, W_{4}\end{array}\right)^{T}$

(C) Determining characteristic vectors of each level

We conduct the following steps to test the consistency of the judgment matrix, and find the weight of each factor: normalize each column of the judgment matrix, therefore we got the judgment matrix A; then we calculate the arithmetic average of each row after normalization, and the results will be divided by the number of factors, thus we obtain the characteristic vector $\mathrm{W}$ of the judgment matrix. The factor Wi of characteristic vector indicateS the relative importance of the factors $i$. If the consistency ratio of the criterion layer is greater than 0.1 , then we should review and revise[21]:

1. Calucate the max characteristic vector root $\lambda \max$ of judgment matrix $A$.

$$
\lambda_{\max }=\frac{1}{n} \sum_{i=1}^{n} \frac{(A w) i}{W i}
$$

Among them, the first i elements $(A W)_{\mathrm{i}}$ for $A W$.

To calculate A consistency check, for example,

$$
A W=\left[\begin{array}{ccccc}
1 & 3 & 3.2 & 2 & \rceil\left[W_{1}\right. \\
0.33 & 1 & 2.25 & 1.5 & \| W_{2} \\
0.31 & 0.44 & 1 & .075 & \| W_{3} \\
0.50 & 0.67 & 1.33 & 1 & \| W_{4}
\end{array}\right]
$$

To put $\mathrm{m}=4$, can be to $\lambda_{\text {max.. }}$

2. Calculate the consistency indicator $\mathrm{CI}$ :

$$
\mathrm{Cl}=\frac{\lambda \max -\mathrm{n}}{\mathrm{n}-1}
$$

When the judgement matrix has consistency, $\lambda \max =0, \mathrm{CI}=0$; When $\lambda \max \neq \mathrm{n}, \mathrm{CI} \neq 0$, the judgement matrix does not have consistency.

3. Identify the average random indicator RI. The common RI coefficients are as follows: 
Table 6. Random Index

\begin{tabular}{lllllllllll}
\hline Betweenness & 1 & 2 & 3 & 4 & 5 & 6 & 7 & 8 & 9 \\
of Matrix A & & & & & & & & & \\
\hline RI & 0.00 & 0.00 & 0.58 & 0.90 & 1.12 & 1.24 & 1.32 & 1.41 & 1.45
\end{tabular}

4. Calculate the random consistency indicator CR.

$$
\mathrm{CR}=\frac{C I}{R I}
$$

If $\mathrm{CR}<0.10$,then the judgment matrix is considered having satisfactory consistency. . If CR is greater than 0.10 in the detection, then it should be amended to give a set of values so long as the CR can be less than 0.10 .

By using the above mentioned methods, we obtain the indicator level rank weights of each levels in terms of its importance relative to the objective level:

Table 7. The Indicator Level Rank Weights of Each Levels in terms of its Importance Relative to the Objective Level

\begin{tabular}{|c|c|c|c|c|c|}
\hline Criterion & $\begin{array}{c}\text { B } \\
47.5 \%\end{array}$ & $\begin{array}{c}\mathrm{C} \\
20.1 \%\end{array}$ & $\begin{array}{c}\mathrm{D} \\
10.4 \%\end{array}$ & $\begin{array}{c}\mathrm{E} \\
22.0 \%\end{array}$ & $\begin{array}{l}\text { Indicator Level } \\
\text { Rank Weights }\end{array}$ \\
\hline Indicator & & & & & \\
\hline $\mathrm{B}_{1}$ & $22.5 \%$ & & & & $10.7 \%$ \\
\hline $\mathrm{B}_{2}$ & $31.0 \%$ & & & & $14.7 \%$ \\
\hline $\mathrm{B}_{3}$ & $13.5 \%$ & & & & $6.4 \%$ \\
\hline $\mathrm{B}_{4}$ & $9.3 \%$ & & & & $4.4 \%$ \\
\hline $\mathrm{B}_{5}$ & $17.4 \%$ & & & & $8.3 \%$ \\
\hline $\mathrm{B}_{6}$ & $6.3 \%$ & & & & $3.4 \%$ \\
\hline $\mathrm{C}_{1}$ & & $34.5 \%$ & & & $6.9 \%$ \\
\hline $\mathrm{C}_{2}$ & & $65.5 \%$ & & & $13.2 \%$ \\
\hline $\mathrm{D}_{1}$ & & & $33.1 \%$ & & $3.4 \%$ \\
\hline $\mathrm{D}_{2}$ & & & $66.9 \%$ & & $7.0 \%$ \\
\hline $\mathrm{E}_{1}$ & & & & $24.5 \%$ & $5.4 \%$ \\
\hline $\mathrm{E}_{2}$ & & & & $48.3 \%$ & $10.6 \%$ \\
\hline $\mathrm{E}_{3}$ & & & & $27.2 \%$ & $6.0 \%$ \\
\hline
\end{tabular}

$\mathrm{CI}=0.061 \quad \mathrm{RI}=0.835 \quad \mathrm{CR}=0.073$




\section{(D) Performance Analysis}

Is one of the main purpose of the enterprise performance evaluation to the final conclusion, and form the evaluation conclusion is the main process of the evaluation object based on the evaluation index of the decomposition, measured by the evaluation index, evaluation of each part, conclusion of evaluation objects and the calculation method of monomial evaluation and then according to certain of the comprehensive evaluation value of the final evaluation object will conclude comparing with standard value, the integrated evaluation form the evaluation results.

Calculation steps are as follows:

(1) Determine the direction.

(2) Standardizing.

Due to the index system of each index in the dimension is different, different dimension can be understood as indicators of measurement attributes, such as some indicators unit is ten thousand yuan, some indicators unit for days. In the order of different dimensional will get different covariance matrix or correlation matrix, in order to ensure objectivity of evaluation results and scientific, standardized processing to the original data, the calculating formula for:

$$
Y_{\mathrm{i}}=\left(X_{\mathrm{i}}-x\right) / s
$$

$X_{i}$ as evaluation indexes of this period the actual value, $x$ is the index of average, $S$ as the index all the sample standard deviation.

(3) The standardized score results. If positive indicators on the results of standardized scores, and reverse index is multiplied by sucking in a"-1 "for the score.

(4) Calculate individual indicators. As the weight of each index on the result of step score of adjustment, and the score results with the weight of the product is a single parameter.

(5)Score and total score value calculated in different aspects. Will a dimension score of aggregation, the indicators reflected the dimension performance score to score four dimensions of aggregation, namely company's comprehensive performance score.

By using an objective, scientific and rigorous design principles, based on the original design, we refine the indicators and construct the specific indicators of performance evaluation, as described in reference [11]. In this paper, we use the comprehensive statistical data in 2014 from the five automobile companies we actually investigate as a basis to calculate the performance evaluation. The specific control indicators and basic data are as in Table 8 below. 
Table 8. BSC Index Control Sheet

\begin{tabular}{|c|c|c|c|c|c|c|}
\hline Level & Indicator & Unit & Attribute & $\begin{array}{l}\text { Annual } \\
\text { Target }\end{array}$ & $\begin{array}{c}\text { Annual } \\
\text { Completion }\end{array}$ & $\begin{array}{l}\text { Completion } \\
\text { Rate }\end{array}$ \\
\hline \multirow{6}{*}{ 呇 } & $\begin{array}{l}\text { Operating } \\
\text { Revenue }\end{array}$ & 0,000 & Positive & $1,869,125.00$ & $2,009,170.92$ & $107.49 \%$ \\
\hline & Net Profit & 0,000 & Positive & $11,286.54$ & $34,216.15$ & $303.16 \%$ \\
\hline & $\begin{array}{l}\text { Total Cash } \\
\text { Flow }\end{array}$ & 0,000 & Positive & $197,422.50$ & $329,385.34$ & $166.84 \%$ \\
\hline & $\begin{array}{l}\text { Total Assets } \\
\text { Turnover }\end{array}$ & $\%$ & Positive & $100 \%$ & $162.38 \%$ & $162.38 \%$ \\
\hline & R\&D Expense & 0,000 & Negative & $11,272.27$ & 8831.33 & $78.34 \%$ \\
\hline & $\begin{array}{l}\text { Selling } \\
\text { Expense }\end{array}$ & 0,000 & Negative & $97,744.03$ & $116,879.31$ & $119.58 \%$ \\
\hline \multirow{2}{*}{ 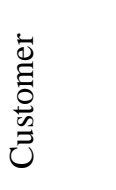 } & $\begin{array}{l}\text { Customer } \\
\text { Satisfaction }\end{array}$ & $\%$ & Positive & $90 \%$ & $89.75 \%$ & $99.7 \%$ \\
\hline & $\begin{array}{l}\text { Customer } \\
\text { Loyalty }\end{array}$ & $\%$ & Positive & $85 \%$ & $79.5 \%$ & $93.53 \%$ \\
\hline \multirow{2}{*}{ 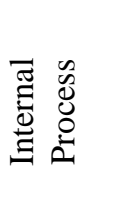 } & $\begin{array}{l}\text { Product } \\
\text { Development } \\
\text { Capacity }\end{array}$ & $\begin{array}{l}\text { number/d } \\
\text { ay }\end{array}$ & Positive & 280 & 240 & $85.71 \%$ \\
\hline & $\begin{array}{l}\text { After-sales } \\
\text { Service Fee }\end{array}$ & 0,000 & Negative & $17,240.61$ & $10,931.35$ & $-63.4 \%$ \\
\hline \multirow{3}{*}{ 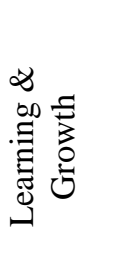 } & $\begin{array}{l}\text { Employee } \\
\text { Training }\end{array}$ & $\begin{array}{l}\text { hour/ } \\
\text { person }\end{array}$ & Moderate & 40 & 28.8 & $72 \%$ \\
\hline & $\begin{array}{l}\text { Employee } \\
\text { Compensation }\end{array}$ & $\begin{array}{l}\text { RMB } \\
\text { yuan }\end{array}$ & Moderate & 2870 & 2450 & $85.37 \%$ \\
\hline & $\begin{array}{l}\text { Employee } \\
\text { Satisfaction }\end{array}$ & $\%$ & Positive & $80 \%$ & $80 \%$ & $100 \%$ \\
\hline
\end{tabular}

(Source: Automobile Industry Internal Annual Report)

Note: Bias ratio $=\frac{\text { AnnualComl petion }- \text { AnnualT } \arg \text { et }}{\text { AnnualT } \arg \text { et }} * 100 \%$

Calculate the composite score. The composite score of each level equals to the total sum of each completed indicators times each indicator's weight. For the positive indicators, the calculate results will be the final results using the above method; while for the negative indicator (contrary indicator), the results need to be multiplied by " -1 " to get the final results. The results obtained are shown in Table 10 below: 
Table 9. Operating Comprehensive Performance Evaluation in 2014

\begin{tabular}{|c|c|c|c|c|c|}
\hline \multicolumn{2}{|c|}{ Level } & Indicator Weight & Weight & Completion Rate & Score \\
\hline \multirow{6}{*}{\multicolumn{2}{|c|}{ 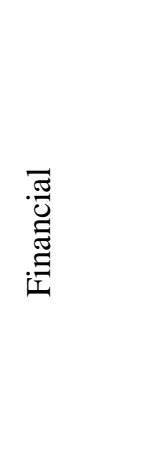 }} & Operating Revenue & $10.7 \%$ & $107.49 \%$ & 11.50 \\
\hline & & Net Profit & $14.7 \%$ & $303.16 \%$ & 44.56 \\
\hline & & Total Cash Flow & $6.4 \%$ & $166.84 \%$ & 10.68 \\
\hline & & Total Assets Turnover & $4.4 \%$ & $162.38 \%$ & 7.14 \\
\hline & & R\&D Expense & $8.3 \%$ & $78.34 \%$ & -6.50 \\
\hline & & Selling Expense & $3.4 \%$ & $119.58 \%$ & -4.07 \\
\hline \multirow{2}{*}{\multicolumn{2}{|c|}{$\begin{array}{l}\bar{\Phi} \\
\stackrel{0}{0} \\
\stackrel{0}{0} \\
\vec{U}\end{array}$}} & Customer Satisfaction & $6.9 \%$ & $99.7 \%$ & 6.88 \\
\hline & & Customer Loyalty & $13.2 \%$ & $93.53 \%$ & 12.35 \\
\hline & & Product Development & $3.4 \%$ & $85.71 \%$ & -2.91 \\
\hline & 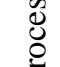 & Capacity & & & \\
\hline & & After-sales Service Fee & $7.0 \%$ & $-63.4 \%$ & 4.43 \\
\hline \multirow{3}{*}{ 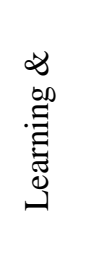 } & & Employee Training & $5.4 \%$ & $72 \%$ & 3.89 \\
\hline & 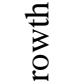 & Employee Compensation & $10.6 \%$ & $85.37 \%$ & 9.05 \\
\hline & & Employee Satisfaction & $6.0 \%$ & $100 \%$ & 6.00 \\
\hline
\end{tabular}

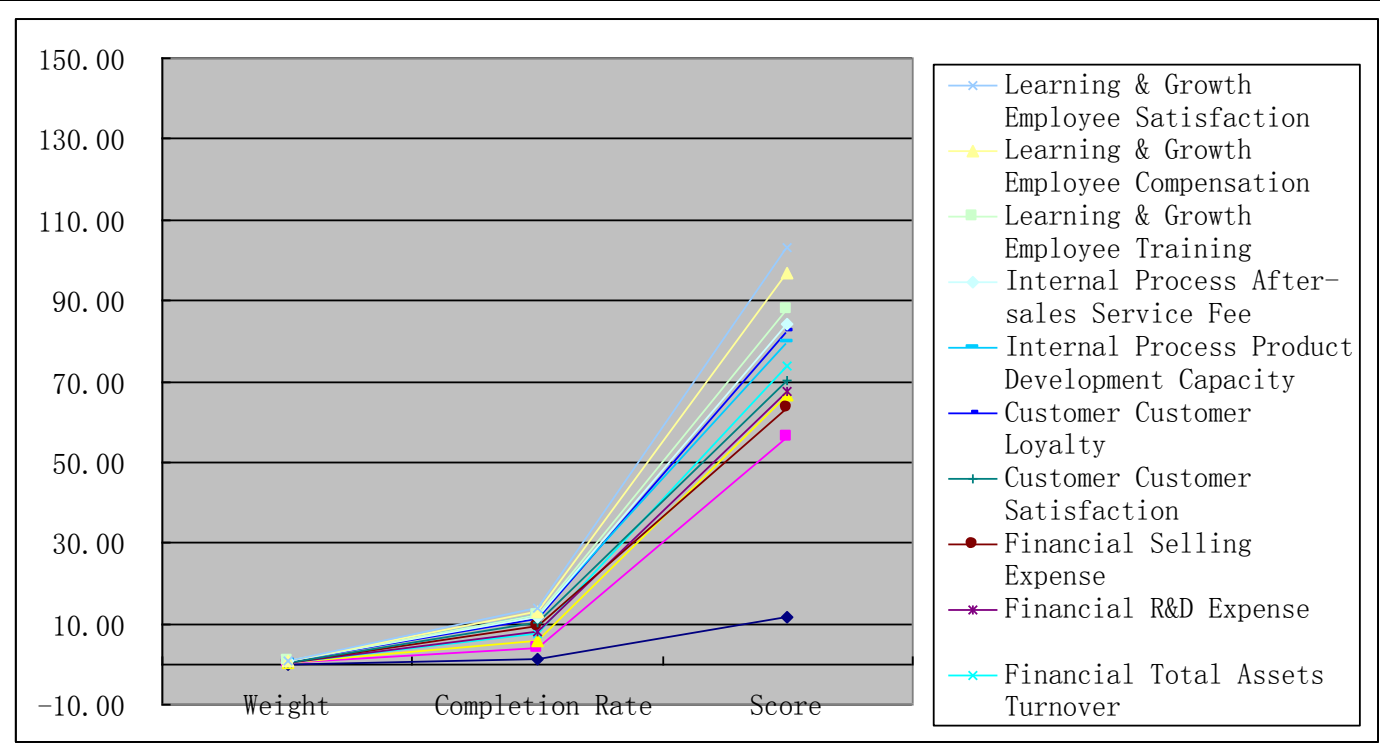

Figure 3. 2014 Operating Comprehensive Performance Evaluation Analysis Diagram 
Table 10. Comprehensive Score of each Level

\begin{tabular}{ccc}
\hline Level & Weight & Score \\
\hline Financial & $47.5 \%$ & 62.68 \\
Customer & $20.1 \%$ & 19.23 \\
Internal Process & $10.4 \%$ & 1.52 \\
Learning \& Growth & $22.0 \%$ & 18.94 \\
\hline
\end{tabular}

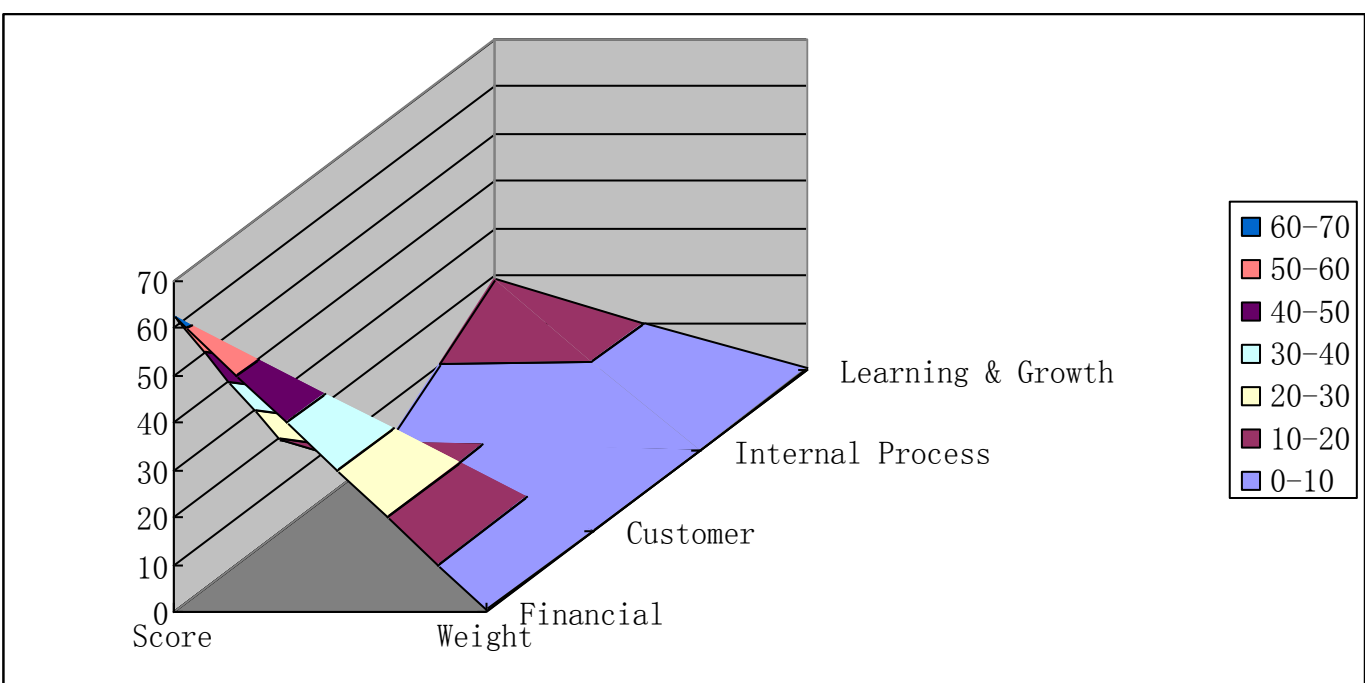

Figure 4. BSC's class A Comprehensive Performance Evaluation

(E) Comprehensive evaluation and improvement measures

From the five auto companies' performance evaluation results in 2014, as can be seen in all the assessment indicators, financial indicators account for the largest share of $47.5 \%$ for companies to achieve their strategic goals, which is far higher than other indicators, thus financial indicators require enterprises pay more attention in long-term development. Meanwhile, net profit and operating revenue in the financial level account for a large proportion, accounting for $14.7 \%$ and $10.7 \%$ of the total respectively. In order to achieve enterprises' strategic objectives, it would require enterprises pay more attention to the operating revenue, and reduce the selling expense, thus to achieve the enterprise's net profit targets. 


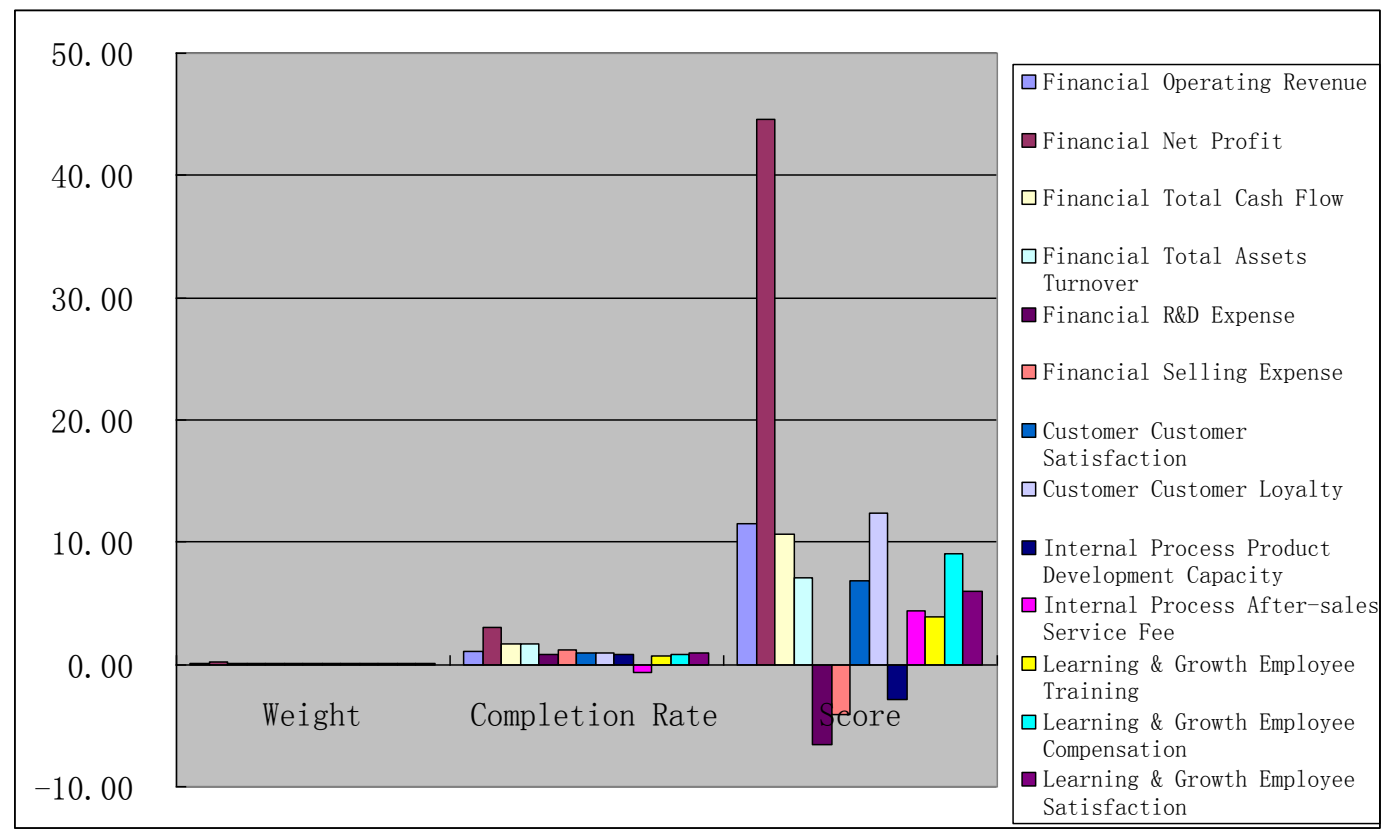

Figure 5. 2014 Five Motors Performance Evaluation Results of the Analysis

In terms of customers, customer loyalty in the development of enterprises also played an important role. The increasing of customer loyalty (13.2\%) will bring a corresponding increase in product sales. In order to retain customers and maintain the long-term source of enterprise development, we must attach great importance to customer service, and keep improving the service system.

In terms of the internal process, the enterprise need to set up a highly professional research team to strictly implement the corporate Research \& Development program, as well as manage the research team to enhance the ability to develop new products. These are the most important factors to the long-term development of enterprises. When the enterprise is able to keep proposing new products to the market, it can win over customers and capture the market.

In terms of learning and growth, the enterprise need to establish and keep improving the staff training system in the long run. Human resources are valuable assets for the enterprises, the intellectual capital in the development of enterprises plays an increasingly important role. To enhance the quality of human resources will require long-term training for the staff, and meanwhile rational salary systems and incentive mechanisms need to be built in order to retain the talents.

One important measure to achieve non-financial indicators are to promote the corporate culture, mobilizing the people in the enterprise to fight together to achieve the same strategic objective. What's more, the organizational culture should have a certain degree of tolerance, accept the errors, and encourage creativity and collaboration. In the high-tech enterprises, the establishment of learning-oriented team culture is an essential requirement for new product development organization. The organization can evaluate and remunerate the performance of the team members based on their actual contribution. Such remuneration is not necessarily in monetary terms, but need to offer some recognition to the employee's learning and growth behavior. The enterprise should adopt the incentive mechanisms in three areas, namely extrinsic rewards, intrinsic rewards and self-efficacy, these incentive also should be sustained in the long-term development. 


\section{Conclusion and Future Research}

Since the BSC was introduced to China, it has received high recognition among scholars. On the basis of foreign study, Chinese scholars push forward the study of BSC, and make it plays a significant role to help high-tech enterprises in risk performance evaluation. As an important strategic performance management tool, the introduction of the four evaluation indicators, including non-financial indicators. This paper gives design principles of its risk investment performance evaluation, and makes an empirical study about five auto companies on the performance evaluation of risk investment based on the BSC, to make up for the drawback of traditional performance appraisal which pays too much attention to the financial indicators and provide a useful exploration for the comprehensive evaluation of risk investment performance of High-tech Enterprise and redress effectively the over-emphasis on financial indicators in traditional performance evaluations:(1) avoid the short-term perspective in corporate financial evaluation method; (2) unify the organization's action to serve the enterprise's strategic objectives; (3) effectively convert the enterprise's strategic goals into performance indicators and actions in different levels; (4) enable employees from all levels in the organization to communicate and understand the enterprise's objectives and strategies; (5) cultivate the enterprise and employees' learning, growth and core competencies; (6) achieve long-term organizational development; (7) improve the organization's overall management through the implementation of BSC.

Therefore, based on the previous studies and the performance evaluation of five auto companies based on the BSC method, we have identified the key indicators for enterprises to achieve their strategic objectives, namely the enterprise's operating revenue, net profit, customer loyalty, and R\&D investment etc. Meanwhile, due to some limitations of this study and the research team's ability, this paper remains to be studied in-depth. The authors' future research directions and specific topics would focus on the dynamic development of indicators in evaluating performance of high-tech enterprises' risk investment, and the multidimensional issues of the indicators from different levels and other issues are yet to be resolved.

\section{Acknowledgments}

The work of K. Lu is partly supported by the National Science Fund for Distinguished Young Scholars under Grant No.71225002; Key Projects of Revitalization Plan in Colleges and Universities in Anhui Province No.2013zytz080.

\section{References}

[1] J. C. Hayton, "Competing in the New Eeonomy: the Effect of Intellectual Capital on Corporate Entrepreneurship in High-technology New Ventures”, R\&D Management, vol. 35, (2005), pp. 137-155.

[2] L. Jianli, Analysis of the convergence of BSC and EVA", Finance and Accounting Monthly (Theory), vol. 8, (2006), pp. 69-70.

[3] F. Hong, W. Min and P. Yueqi, "Venture capital to promote high-tech enterprise development: the role of financial support and management support", Scientific and technological progress and Countermeasures, vol. 11, (2012), pp. 1-4.

[4] Z. Xiaozhi, "The research on the performance evaluation of venture capital in small and medium sized scientific and technological enterprises", Taiyuan University of Technology, (2013).

[5] L. Kebin, W. Qiang and Z. Hui, "Research on the venture capital of small and medium enterprises based on technological innovation", Management modernization, vol. 1, (2013), pp. 16-18. 
[6] Q. Rong, "Study of the influence of political connection and venture capital on Enterprise Performance-Empirical evidence based on private small and medium sized enterprises in China", Southwestern University of Finance and Economics, (2014).

[7] R. S. Kaplan and D. P. Norton, "The Balanced Score Card-Measures that Drive Performance, Harvard Business Review”, (1992) January- February, pp. 71-79.

[8] Z. Daohai and Z. Tongjian, "Research on the performance evaluation system of high tech small and medium risk enterprises based on Balanced Score Card", Financial Communication, vol. 12, (2010), pp. 19-20.

[9] T. Jing, "Analysis of financial crisis early warning based on BSC", Shopping malls Modern Magazine, vol. 12, (2010), pp. 185.

[10] Z. Meiqun and W. Yan, "Performance evaluation of high tech enterprises based on intellectual capital”, Journal of Northeast Normal University, vol. 4, (2004), pp. 60-66.

[11] J. Huaijing, "Research on performance management of T company based on Balanced Score Card”, Beijing University of Posts and Telecommunications, vol. 3, (2008).

\section{Author}

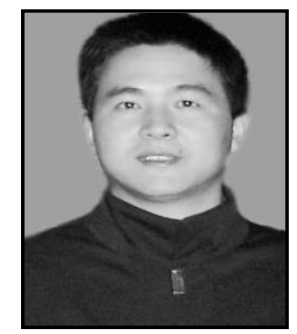

Lu Kebin, he is currently an Associate Professor and Vice president of Commercial College, Anhui Xinhua University. His current interests include management science and Engineering. 